3. Young RP, Hopkins RJ, Smith M, et al. Smoking cessation: the potential role of risk assessment tools as motivational triggers. Postgrad Med J 2010;86:26-33.

4. Young RP, Hopkins RJ, Whittington CF, et al. Individual and cumulative effects of GWAS susceptibility loci in lung cancer: associations after sub-phenotyping for COPD. PLoS One 2011;6:e16467.

5. Hopkins RJ, Young RP, Hay B, et al. Gene-based lung cancer risk score triggers smoking cessation in randomly recruited smokers. Am J Respir Crit Med 2011;183:A5441.

\section{Need to test impact of DNA-based risk scores}

Young and Hopkins highlight the emerging data suggesting that smokers who perceive themselves at a lower risk of lung cancer may be less likely to take part in, and less likely to adhere to, lung cancer screening programmes. $^{1-4}$ Their work suggesting that a risk score that includes genetic markers of susceptibility of lung cancer alters optimistic bias, improves quit rates in smokers and may encourage participation in lung cancer CT screening is exciting.

Risk scores that include genetic risk data may reach the parts that other risk scores fail to reach. In the lung-SEARCH screening trial, we found that a negative family history specifically led some smokers to decline participation in screening. Being told that risk of lung cancer is 'in your genes' may specifically counter perceptions of protection from a negative family history. This proposal could be tested with further qualitative exploration of risk perception in smokers offered participation in screening trials However, in a Cochrane review of the literature, Marteau et al ${ }^{5}$ found no overall impact of presenting DNA-based risk scores, although studies are few and of variable quality.

Lung cancer screening programmes especially need to target those at the highest risk in order to maximise cost effectiveness. DNA-based risk profiling may contribute to better targeting for those enrolling in lung cancer screening programmes. This too needs to be tested prospectively.

Chris Griffiths, ${ }^{1}$ Deesha Patel, ${ }^{1}$ Ajiri Akporobaro, ${ }^{1}$ Nyasha Chinyanganya, ${ }^{2}$ Allan Hackshaw, ${ }^{3}$ Clive Seale, ${ }^{1}$ Robert Walton, ${ }^{1}$ Stephen Spiro ${ }^{4}$

${ }^{1}$ Centre for Primary Care and Public Health, Blizard Institute, Queen Mary, University of London, London, UK; ${ }^{2}$ Department of Thoracic Medicine, University College London Hospital NHS Foundation Trust, London, UK; ${ }^{3}$ Cancer Research UK and University College London Cancer Trials Centre, London, UK; ${ }^{4}$ Royal Brompton Hospital, London, UK
Correspondence to Chris Griffiths, Centre for Primary Care and Public Health, Blizard Institute, Queen Mary, University of London, London, UK; c.j.griffiths@qmul.ac.uk

\section{Competing interests None.}

Provenance and peer review Commissioned; internally peer reviewed.

Accepted 7 January 2012

Published Online First 28 February 2012

Thorax 2012;67:835.

doi:10.1136/thoraxjnl-2012-201596

\section{REFERENCES}

1. Patel D, Akporobaro A, Chinyanganya N, et al Attitudes to participation in a lung cancer screening trial: a qualitative study. Thorax 2012;67:418-25

2. van den Bergh KA, Essink-Bot ML, van Klaveren RJ, et al. Informed participation in a randomised controlled trial of computed tomography screening for lung cancer. Eur Respir $J$ 2009:34:711-20.

3. Montes U, Seijo LM, Campo A, et al. Factors determining early adherence to a lung cancer screening protocol. Eur Respir J 2007;30:532-7.

4. Silvestri GA, Nietert PJ, Zoller J, et al. Attitudes towards screening for lung cancer among smokers and their non-smoking counterparts. Thorax 2007:62:126-30.

5. Marteau TM, French DP, Griffin SJ, et al. Effects of communicating DNA-based disease risk estimates on risk-reducing behaviours. Cochrane Database Syst Rev 2010;(10):CD007275. 